\title{
Electrochemical Investigation of Carbon Paste Biosensor Bound with Natural Rubber Solution
}

\author{
Beom-Gyu Lee, Keun-Bae Rhyu, ${ }^{\dagger}$ and Kil-Joong Yoon ${ }^{*-}$ \\ Department of Chemistrv, Chosm Lniversitw, Kwangiu 501-759. Korea \\ -Division of Applied Sciences, Cheongit Lnwersity, Cheongiu 360-764, Korea. "E-mail: Kjoonaciuac.kr \\ Received March 10. 2009. Accepted Alugust 24, 2009
}

Key Words: Biosensor. Peroxide. Peroxidase. Carbon paste electrode. Natural rubber

The rate of reactions catalyzed using enzy mes is more than a million times higher compared to cases without catalysis. There have been a lot of efforts to make and put to use a biosensor using this catalytic specificity of enzymes. Here. it is very important to immobilize an enzyme to keep its specificity on the surface of the biosensor. In order to do this, many methods have been developed such as using the physical adsorption property of the enzyme. ${ }^{3}$ the covalent bonding ability of the enzyme with a functional poly mer. ${ }^{2}$ the poly mer film ${ }^{3}$ and the immobilization of the enzyme in a mixture of electrode material. especially, sol-gel, with the enzyme source, ${ }^{4,5}$ In this lab. various graphite electrodes using mineral oil as a binder have been made and their electrochemical characteristics have been studied. ${ }^{6}$ This method achieves very high efficiency in the aspects of cost and time for making the biosensor compared with the previously mentioned methods since it does not require tedious physical and/or chemical procedures. This method is still used efficiently in the field of research about characteristics of enzy'mes. So that the binder may be of much use in actual life. the mechanical stability of the electrode should be guaranteed. However we cannot expect such stability from mineral oil. We had been trying to find a binder of graphite to ensure the mechanical property in order to obviate this inadequacy of mineral oil. The inquiry revealed a surprising fact that the rubber liquefied in toluene shows mechanical stability if the solvent is volatilized during the final stage of making the electrode. As a result. electrodes using various kinds of rubbers such as ethylene propylene diene terpolymer ? polybutadiene nibber. ${ }^{8}$ butyl rubber" and chloroprene nibber ${ }^{\text {it }}$ have been made and their applicability has been studied and reported in related research. Research activities revolving around this are increasing at this time.

The natural rubber molecules consist virtually entirely of cis-1.4-polyisoprene which has no evidence for any trans material or for any 1,2-or 3.4-isoprene polymer. in contrast to the synthetic poly isoprenes. It is known that natural nibber has a better shelf life than synthetics and has a high wet gel strength even at low temperatures. ${ }^{\text {l] }}$ It also attains the excellent characteristics of membrane strength and elasticity. which cannot be expected from synthetics. Expecting that those characteristics should satisfy the pre-requisite conditions for application. we have constructed an enzyme electrode for the determination of hydrogen peroxide. In this context. we report its details here.

\section{Experiments}

Reagents and Measurements. The ground root tissue of cabbage was used as a source of enzymes and natural rubber (NR, RSS\# 1, Mooney viscosity: 61, density: 0.92) was a product of Malaysia. Toluene and graphite powder were purclased from Sigma-Aldrich $(\geq 99.9 \%)$ and from Fluka $(\leq 0.1 \mathrm{~mm})$ respectively. Hydrogen peroxide (Junsei. EP. 35\%) for substrate (abbr. S). $\mathrm{NaCl}$ (Shinyo pure Chem. $\geq 99.5 \%$ ) for electrolyte and ferrocene (Sigma) for the mediator to increase and stabilize the signal were used. $\mathrm{Ag} / \mathrm{AgCl}$ (BAS MF2052) and Pt electrode (BAS MW 1032) were used for the reference and for auxiliany electrodes, respectively. The enzy me electrode was connected to a BAS Model EPSILON (Bioanalytical System, Inc., U. S. A.) to obtain cyclic voltammograms. The other amperometric measurements were performed with EG\&G Model 362 potentiostat (Princeton Applied Resaerch. U. S. A.). Its output was recorded on a Kipp \& Zonen x-t strip chart recorder (BD111, Holland). Origin 7 was utilized for all the calculations.

Construction of Enzyme Electrode. After dissolving $0.09 \mathrm{~g}$ of ferrocene in $10 \mathrm{~mL}$ of $\mathrm{CHCl}_{3} .0 .91 \mathrm{~g}$ of the graphite powder was added and then dried. By mixing $1.0 \mathrm{~g}$ of the produced graphite powder with the solution of natural rubber $(1.5 \%)$ at a $1: 1$ ratio $(w t / w t)$, carbon paste was made. $1 \mathrm{~g}$ of this paste was completely mixed with $0.1 \mathrm{~g}$ of the ground cabbage root. The biosensor was designed by packing the paste into a $6 \mathrm{~mm}$ i. d. and $2 \mathrm{~mm}$ depth polyethylene tube having olumic contact. It was smoothed by friction on a spatula to make a flat working surface. The cyclic voltammograms were obtained in the states of both the unstirred and stirred solution by the placement of the working electrode. Amperometric current was obtained as follows. When the decreasing tendency of the charging current keeps horizontal after applying the step potential on the working electrode. substrate solution is added in $10 \mathrm{~mL} 0.1 \mathrm{M} \mathrm{NaCl}$ solution. Then the current difference between before and after adding the solution was considered to be the decomposition current of hydrogen peroxide.

\section{Results and Discussion}

Figure 1 shows the comparison of the cyclic voltammograms before(a) and after(b) adding substrate $\mathrm{H}_{2} \mathrm{O}_{2}$ in the system. It shows the increase of the reduction current according to the electrode potential increases in a negative direction 
in the electrolytic solution when it does not contain the substrate (a-1). In the case of a glassy carbon electrode. this sy'stem does not yield any reduction current in this potential range. ${ }^{\text {lo }}$ However. we may take various electrochemical reactions into our consideration since the enzyme electrode which is used in this work contains mediator, ferrocene. electrolytic solvent and nibber. First of all with ferrocene as a mediator. the standard reduction potential of the ferricinium ion was $0.400 \mathrm{~V}$. It seems that the influence of the reduction function of the ferricinium ion is not great in the experimental range of potential. Also. we note that the current increases rapidly above $-1.5 \mathrm{~V}$. The standard reduction electrode of water is $-0.828 \mathrm{~V}$. However. we may expect that the enzyme electrode will undergo large overvoltage compared with the Pt elec-

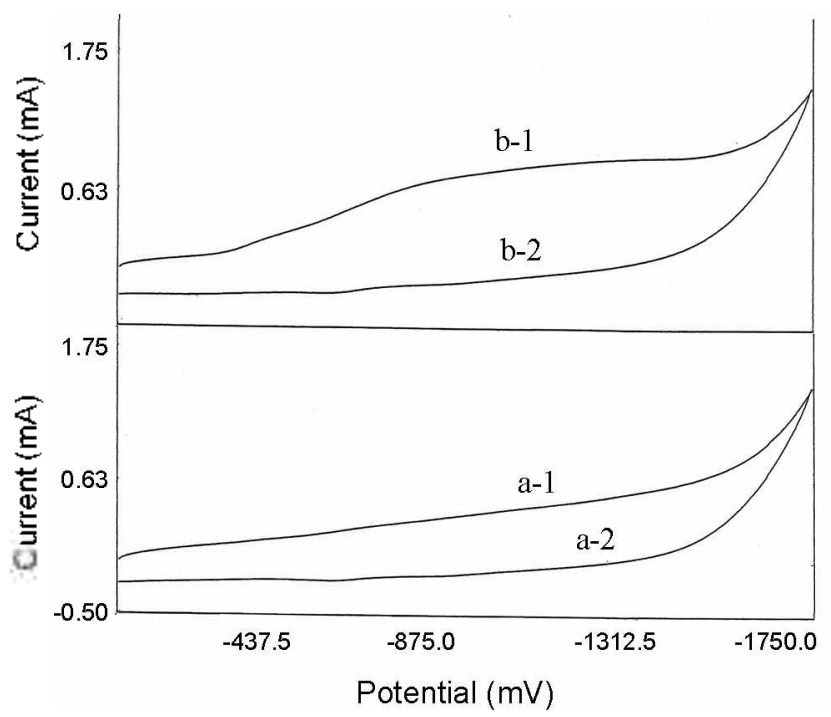

Figure 1. Comparison of cyclic voltammogram without (a) and with (b) adding substrate $\left(0.1 \mathrm{M} \mathrm{H}_{2} \mathrm{O}_{-} 100 \mu \mathrm{L}\right.$ ) in an unstimed $10.0 \mathrm{~mL}$ of $0.1 \mathrm{M} \mathrm{NaCl}$ solution. 1 and 2 are the direction of the forward and the reverse scan respectively. Initial potential: $0.0 \mathrm{~V}$, switching potential: $-1.8 \mathrm{~V}$, scan rate: $100 \mathrm{mV} / \mathrm{sec}$.

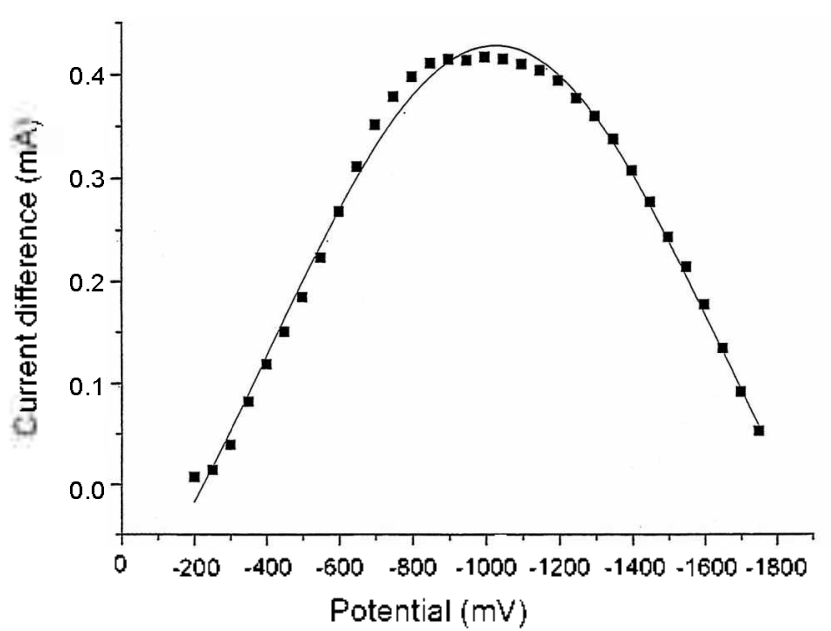

Figure 2. Calculated current difterence between b- 1 and a-l with applied electrode potential in Figure 1. Solid line: $y=y 0+(\mathrm{A} /$

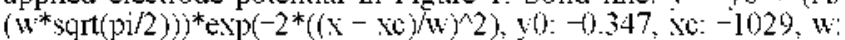
$1267 . \mathrm{A}: 1230$. trode even though we cannot explain the precise cause. The reason is conjectured as follows. Since we can see the air bubbles with the naked eve during electrolysis at above -1.5 $V$. it would be no problem to consider the lugh current at above $-1.5 \mathrm{~V}$ as the current of reduction of water. Rubber is a complex nixture with various components. Therefore, the linearly increasing current with electrode potential can be attributed to electrochemical reactions among the components of rubber. It can be seen that a- 1 is deformed to b-l after adding the substrate. $\mathrm{H}_{2} \mathrm{O}_{2}$ in the electrolytic solution. Since thus change comes from the addition of $\mathrm{H}_{2} \mathrm{O}_{2}$ whule maintaning the same conditions. one may consider it to be the contribution of the reduction current of $\mathrm{H}_{2} \mathrm{O}_{2}$. Figure 2 shows the variation in the difference between $a-1$ and $b-1$. The graphic of current difference is approximately symmetric and the normalized result is represented in a solid line. The peak potential $\left(\mathrm{E}_{p}\right)$. which represents the maximum current, is $-1.029 \mathrm{~V}$. In the case where the system is conpletely reversible. $E_{j:}$ has no correlation with the scan speed and $i_{j:}^{\text {res }}$ increases depending on the scan speed. However, when the system is irreversible. $\mathrm{l}_{\mathrm{p}}^{\text {urew }}$ is relevant to $\mathrm{v}^{\text {l: }}$ but the peak potential $\left(E_{F}\right)$, which is the function of potential scan speed changes to the negative - ) direction as $v$ increases for the reduction reaction. Figure 3 is the plot of dependence of $E_{F}$ according to changes in scan speed and shows clearly the tendency of the previously mentioned irreversible system. The electron transfer reaction of ferrous ion and hydrogen peroxide. which happens in bio-organisms. is $\mathrm{Fe}^{2+}+\mathrm{H}_{2} \mathrm{O}_{2} \rightarrow \mathrm{Fe}^{3+}+\mathrm{OH}^{-}+\mathrm{OH}^{-}$and is one electron transfer reaction $(\mathrm{n}=1)^{13-1+}$ In the irreversible system, one may obtain the kinetic parameters ( $i_{i}, \alpha$, etc $)$ in the Tafel area where the overvoltage is relatively high. In other words. the relation between the overvoltage $E$ and $\left.\ln \left\{i_{l, c}-i\right) / i\right\}$ is linear and the slope and intercept are $\mathrm{RT} /$ onf and $(\mathrm{RT} / \mathrm{\alpha nF})$ $\ln \left(\mathrm{i}_{\mathrm{c}} / \mathrm{i}_{\mathrm{l} . \mathrm{c}}\right)$. respectively. The plot of $\mathrm{E} r \mathrm{~s} \cdot \ln \left\{\left(\mathrm{i}_{\mathrm{j}, \mathrm{c}}-\mathrm{i}\right) / \mathrm{i}\right\}$ is in Figure + for the case of $0.427 \mathrm{nLA}$ obtained at $-1.029 \mathrm{~V}$ as $i_{1 . c}$. Here 0.125 and -0.528 are obtained as the values of slope(RT/ onf $)$ and intercept $(R T / \alpha n F) \ln \left(i / i_{1, c}\right)$ respectively. From these we can get 0.21 and $5.62 \times 10^{-3} \mathrm{Acm}^{-2}$ as the values of $\alpha$ and $i_{1+1}$ respectively

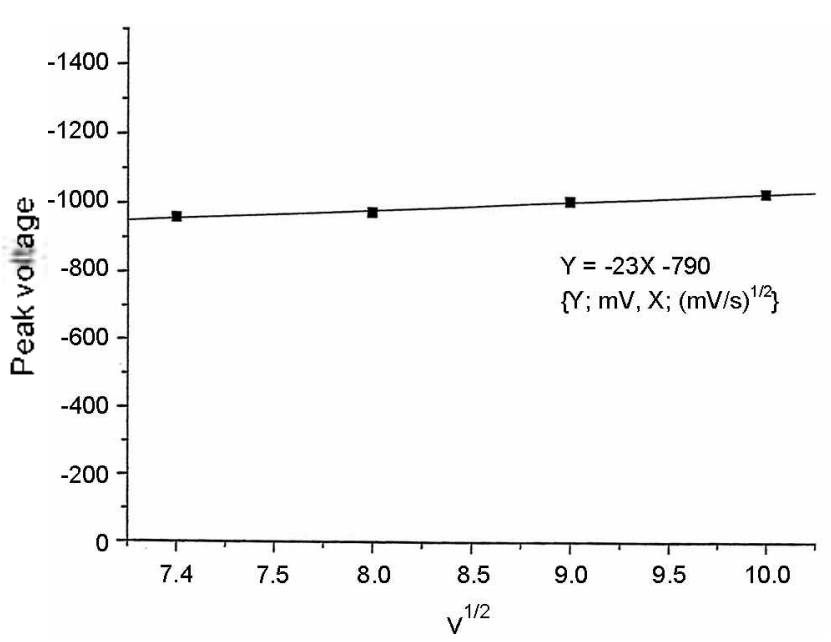

Figure 3. Variation of peak potential with scan speed in $2.0 \times 10^{-2} \mathrm{M}$ $\mathrm{H}_{2} \mathrm{O}_{2}$ solution. 
In the irreversible system. $\left|\mathrm{E}_{\mathrm{p}}-\mathrm{E}_{\mathrm{p} \text { : }}\right|=47.7 / \mathrm{an}(\mathrm{mV})$. Substituting the obtained values for $n$ and $\alpha$, then $\left|E_{p}-E_{p: 2}\right|=239$ $(\mathrm{mV})$. Since this is smaller than the $55 \mathrm{l}(\mathrm{mV})$ obtained from Figure 2, we can hypothesize that this system is irreversible

Figure 5 shows two cyclic voltammograms of enzy'me electrodes in the stirred solution. The advantage of this hydrodynamic amperometry is that condenser current doesn't enter into the measurements because the rate of mass transfer is much larger than that of diffusion. So that the relative contribution of the effect of mass transfer to electron transfer kinetic is smaller. Line a is for the case without substrate and $b$ is for the addition of $0.1 \mathrm{MH}_{2} \mathrm{O}_{2} 100 \mu \mathrm{L}$ in $10 \mathrm{~mL}$ of electrolytic solution. When compared with a in Figure 1, a and b show little difference except for the magnitude of current. Plotting the difference between a and b with the electrode potential. gives a good practical linearity. In contrast with the peak current in the static solution (Figure 2,b-1), it is shown to increase linearly. In this lab. we have observed these tendencles of the current difference with applied potential using various animal and plant tissues. There have been many different cases of

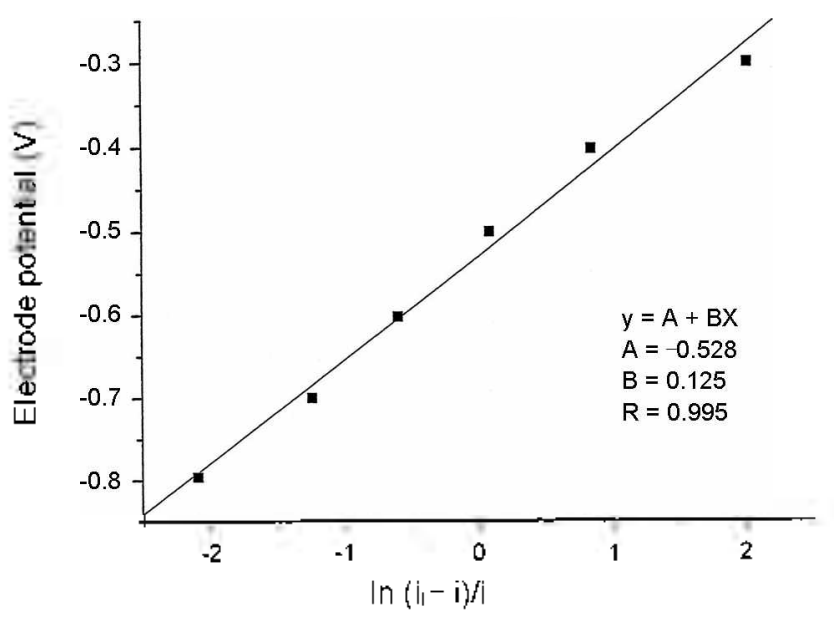

Figure 4. Linear plot of $E$ is. $\ln \left\{\left(i_{1}-i\right) / i\right\}$.

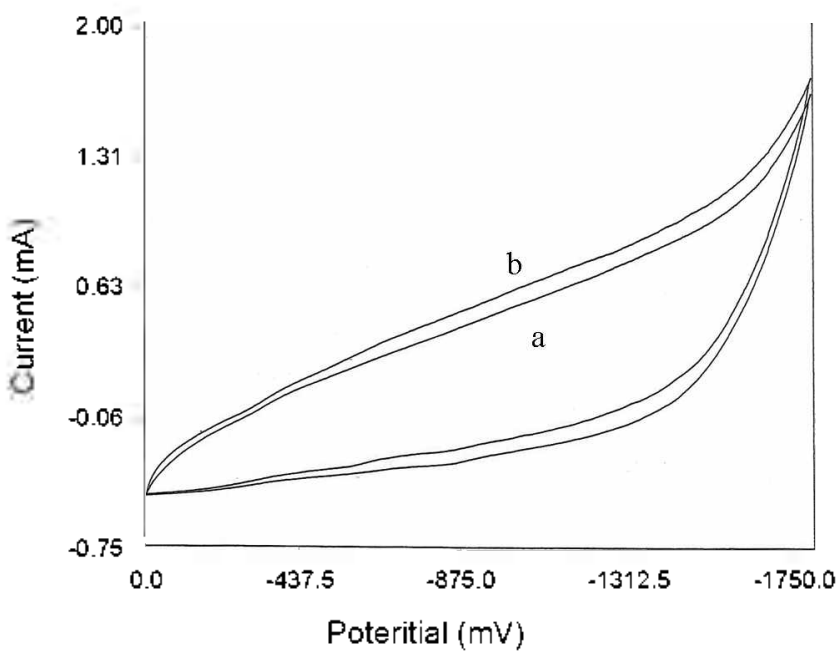

Fiure 5. Cyclic voltammetric response of the bioelectrode in the absense (a) and presense(b) of substrate $\left(1.0 \times 10^{3} \mathrm{M} \mathrm{H}_{2} \mathrm{O}\right.$ ) in a stirred $100 \mathrm{~mL}$ of $0.1 \mathrm{M} \mathrm{NaCl}$ solution. Scan speed: $100 \mathrm{mV} / \mathrm{sec}$. linear increasing. ${ }^{61: 8}$ monotonous increasing. ${ }^{11}$ and independence of the electrode potential. "However, there is no theoretic basis to explain the cause of these changes yet. Table 1 provides the results of observations of the changes for charging current with the lapse time at step potential in the static and stirred solutions. The step potential is $-0.5 \mathrm{~V}$, which is the possible potential for the complete decomposition of $\mathrm{H}_{2} \mathrm{O}_{2}$ as Figure 1 shows. However, maximum current $\left(1_{\max }\right)$ and time constant $(\tau)$ are identical in not being connected with the existence of substrate in the static solution. Here the same maxinum currents without regard to the presence of substrate indicates that the reduction of the substrate makes no contribution to the signal current because of the slow mass transfer in the start of step potential. But $\tau$ with stirring is higher than $\tau$ without stirring with no regard to the existence of substrate. This means that reduction current has been added in the long time span of potential step. Those phenomena reflect the fact that the diffusion of substrate at the active site of the enzyme is relatively slow. On the other hand. one may observe that maximum current in static solutions is higher than that of stirred ones and the time constant is smaller. This can be attributed to convection by the stirring bar disturbing the Levich effect. Figure 6 shows the typical time-current recording at $-0 .+\mathrm{V}$ (vs. $\mathrm{Ag} / \mathrm{AgCl}$ ) in the stirred solution. Within 10 seconds. one may observe that the current is saturated after the addition of substrate. This shows that the enzy me of cabbage root tissue bound by natural rubber is effectively embedded on the elec-

Table 1. i-t behavior resulting from potential step. Step potential: $-0.5 \mathrm{~V}$. Conc. of $\mathrm{H}_{2} \mathrm{O}_{1}: 10 \times 10^{-5} \mathrm{M}$

\begin{tabular}{cccc}
\hline \multirow{2}{*}{ Substrate } & \multicolumn{3}{c}{ Technique } \\
\cline { 2 - 3 } & unstirted & stirted & \\
\hline without & $3.52 / 0.17$ & $3.24 / 0.21$ & $\mathrm{i}_{\max }(\mathrm{mA}) / \tau(\mathrm{sec})$ \\
with & $3.52 / 0.17$ & $3.23 / 0.21$ & \\
\hline
\end{tabular}

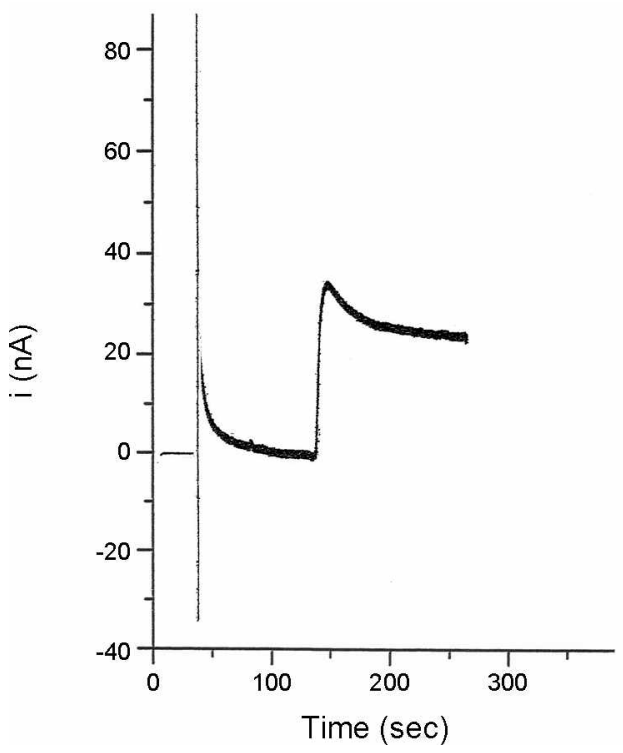

Figure 6. Typical curnent-time response of the bioelectrode. $0.1 \mathrm{M}$ $\mathrm{H}_{2} \mathrm{O}_{2} 50 \mu \mathrm{L}$ was added at $0.4 \mathrm{~V}$ ( v's. Ag/AgCl). 
trode surface. Therefore, this fact implicitly tells us that natural rubber can be utilized as a binder. If a double reciprocal plot of the signal and of the substrate concentration shows linearity. the electrode reaction is through catalysis of the enzyme. This plot sets up a linear equation. $\mathrm{Y}=2.69+5.13 \mathrm{X}\{\mathrm{X}: \mathrm{l} /[\mathrm{S}](\times$ $\left.\left.10^{3} .1 / \mathrm{mM}\right), \mathrm{Y}: 1 / \mathrm{i}\left(\times 10^{6}, 1 / \mathrm{nA}\right), \mathrm{R}=0.999\right\}$. From this. one may conclude that the peroxide of cabbage root tissue. which is embedded by natural nibber play's the role of catalyst on the electrode surface nomally. Also. this proves that natural rubber can be used as a good binder once more. The most influential factor for the signal of a biosensor is the enzyme immobilizing method. The immobilizing method using carbon paste. which has the advantages of easy production and high possibility of applicability, does not show a good detection limit compared with other methods. The detection limit obtained from the electrode used in Figure 6 is $2.5 \times 10^{-4} \mathrm{M}$. This value can be comparable with that $\left(6.7 \times 10^{-4} \mathrm{M}\right)$ of A. N. Diaz et $a .^{16}$ who made HRP electrode with the sol-gel method. but is inferior to that $\left(1.0 \times 10^{6} \mathrm{M}\right)$ of M. Y. Miao et al ${ }^{17}$ The $\mathrm{pH}$ of the solution. the existence and concentration of the mediator. and the content of the enzyme can have additional effects. If those can be optimized. it is clear that the detection limit will be much improved from the present state. Using the chemiluminescence method. J. Wang et d $^{18}{ }^{18}$ obtained $6.42 \times 10^{8} \mathrm{M}$ as its detection limit and $\mathrm{B}$. Tang ${ }^{19}$ achieved $3.89 \times 10^{-19} \mathrm{M}$ using the fluorimetric method. If we consider only the detection limit, the potentiostatic method can not compete with the spectroscopic method. However. it is possible to put this electrode to use and to use it permanently. If more research for the improvement of the detection limit is achieved together. the profits from the advantage of this method may far surpass the costs that the higher detection limit incurs compared to the spectroscopic method.

\section{Conclusion}

It has been demonstrated in this study that natural rubber immobilizes the peroxidase contained in cabbage root tissue to maintain its catalytic power. Also. this proves that natural rubber would be a recommendable binder for applying an enzyme electrode using carbon paste. It offers the possibility of the successful development of a carbon paste biosensor that can be used permanenty. In spite of the feasibility of con- struction and the possibility of application, the sensor made by the method of carbon paste is inferior to the spectroscopic methods in the aspect of detection limit. If studies for the improventent of the detection linit were carried out side by side. then the advantage of a biosensor bound with natural nubber may cover the cost of the disadvantage in detection abiliț:

\section{References}

1. Wang, Z, Jin, G. J. Biochem. Biophss. Methods 2003, 57, 203.

2. (a) Carralero Sanz, V.; Mena, M. L:G González-Cortés, A.; Yáfiez-Sedefio, P.; Pingarrón, J. M. Anal. Chim. Acta 2005, 528 , 1. (b) Itoh, T.; Gotoh, S.; Horii, S.; Hashimoto, $\mathrm{S}$; Uno, T.; Kubo, M.; Fujinami, T; Yamamoto, O.J. Power Sources 2005, 146,371

3. Sergeveva, T. A.; Lavrik, N. V.; Rachkov, A. E.; Kazantseva, Z. I.: Piletsky, S. A.: El'skaya, A. V. Anal Chim Acta 1999, 391 , 289.

4. (a) Miao, Y.: Tan, S. N. Anal Chim .Acta 2001, 437, 87. (b) Lobnik. A.: Cajlakobic. M. Sens. Acmators B 2001.7t 194

5. (a) Crouch, E.; Cowel, D. C.: Hoskins, S.; Pittson, R. W.: Hart, T. P. Biosensois \& Biolectronics 2005, 21, 712 (b) Crouch. E.: Cowel, D. C.; Hoskins, S.; Pittson, R. W: Hart, T. P. Anal. Biochem. 2005, 347, 17. (c) Su, L.; Qiu, X.; Guo, L.; Zhang, F; Tung, C. Sens. Actuators B 2004, 99,499

6. (a) Yoon, K. J. Bull. Koreon Chemt. Soc 2004, 25(7), 997. (b) Yoon, K. J.; Kwon, H. S.; Lee, B. G. J. Kor. Chem. Soc. 2005, $49(3), 325$. (c) Lee. B. G.; Park, S. W.: Yoon, K. J. Anol. Sci. \& Tech, 2006, 19 (1), 58. (d) Yoon. K. I. Ibid 2003, 1666), 504. (e) Lee, B. G.; Kwon, H. S.: Kim, K. E.; Yoon, K. J. lbid 2001, $1+1(3) .286$

7. Yoon. K. J. Elastomer 2007, +2(2), 112

8. Yoon, K J. Anal. Sci. \& Tech. 2007, $20(1), 49$.

9. Yoon. K. J. Elastomer 2006, H(4), 231

10. Yoon, K. J. Bull. Korean Chent. Soc 2008, $29(11), 2264$

11. (a) Stevens, M. P. Polvnter Chemistm, 3rd Ed: Oxford: New York, U. S. A., 1999; p 476. (b) Yoon, K. T. J. Kor. Chem. Soc. 2008, $52(2), 197$

12. Mansouri, A.; Makris, D. P. M.; Kefalas, P. J. Phom. Bio. Anol. 2005, 39, 22 .

13. Graft, E.; Mahoney, I. R.: Bryant, R. G.: Eaton, I. W. J. Biol. Chem. 1984. 259, 3620

14. Henle. E. S.: Linn. S. Ibid 1997, 272, 19095

15. Yoon. K. J. Anal Sci \& Tech $2000,13(1), 41$.

16. Diaz, A. N.: Peinado, M. C. R.; Minguez, M. C. T. Anal Chim. Acta 1998, 363,221

17. Miao, Y: Tan, S. N. Anal. Chm . Acto 2001, 437,87

18. Wang, J; Ye, H.; Jiang, Z; Chen, N, Huang, J. Anal Chim . Acta $2004,508,171$

19. Tang, B.; Wang, Y. Spectrochint. Acta Part A 2003, 59, 2867. 